\title{
The Transition from Downward to Upward Air-Sea Momentum Flux in Swell-Dominated Light Wind Conditions
}

\author{
Ulf Högström, Erik Sahlée, Ann-Sofi Smedman, Anna Rutgersson, And ERik Nilsson \\ Meteorology, Department of Earth Sciences, Uppsala University, Uppsala, Sweden \\ KIMMO K. KAHMA \\ Finnish Meteorological Institute, Helsinki, Finland \\ WILLIAM M. DRENNAN \\ Rosenstiel School of Marine and Atmospheric Science, University of Miami, Miami, Florida
}

(Manuscript received 9 November 2017, in final form 9 May 2018)

\begin{abstract}
Fifteen hours of consecutive swell data from the experiment Flux, État de la Mer, et Télédétection en Condition de Fetch Variable (FETCH) in the Mediterranean show a distinct upward momentum flux. The characteristics are shown to vary systematically with wind speed. A hysteresis effect is found for wave energy of the wind-sea waves when represented as a function of wind speed, displaying higher energy during decaying winds compared to increasing winds. For the FETCH measurements, the upward momentum transfer regime is found to begin for wind speeds lower than about $U=4 \mathrm{~m} \mathrm{~s}^{-1}$. For the lowest observed wind speeds $U<2.4 \mathrm{~m} \mathrm{~s}^{-1}$, the water surface appears to be close to dynamically smooth. In this range almost all the upward momentum flux is accomplished by the peak in the cospectrum between the vertical and horizontal components of the wind velocity. It is demonstrated that this contribution in turn is linearly related to the swell significant wave height $H_{\text {sd }}$ in the range $0.6<H_{\mathrm{sd}}<1.4 \mathrm{~m}$. For $H_{\mathrm{sd}}<0.6 \mathrm{~m}$, the contribution is zero in the present dataset but may depend on the swell magnitude in other situations. It is speculated that the observed upward momentum flux in the smooth regime, which is so strongly related to the cospectral peak at the dominant swell frequency, might be caused by the recirculation mechanism found by Wen and Mobbs in their numerical simulation of laminar flow of a nonlinear progressive wave at low wind speed.
\end{abstract}

\section{Introduction}

Several theoretical studies of air-swell interaction, for example, Sullivan et al. (2008) and Hanley and Belcher (2008), predict that during certain conditions the surface stress should be opposed to the wind, implying an upward transport of momentum. Field measurements have provided some evidence that such regimes do exist, see, for instance, Volkov (1970) and more recently Smedman et al. (1994), Drennan et al. (1999a), and Grachev and Fairall (2001). However, the results have been inconclusive. Direct pressure-wave correlation measurements over wind-following swell-that is, swell traveling in roughly the same direction as the wind (Kahma et al. 2016) - show that the momentum and energy flux spectral contributions

\footnotetext{
Corresponding author: Erik Sahlée, erik.sahlee@met.uu.se
}

are upward for those wave components that are faster than the local wind, whereas the flux contributions are downward for components that are slower than the local wind. Högström et al. (2009, 2013), as well as the abovementioned modeling studies, show that in the presence of wind-following swell, the wind velocity above $7 \mathrm{~m}$ over the mean sea level is close to height constant; thus, the height where the local wind is measured is not critical. Thus, the task of this paper is to analyze available low wind speed data from a marine field experiment to clarify the properties of this regime.

In a recent study by Högström et al. (2015) it was found that momentum is transferred downward in swell conditions with moderate wind in a turbulent regime where the mean phase angle between the longitudinal and vertical components is close to zero. In this regime, observed in the velocity range $3.5<U<10 \mathrm{~m} \mathrm{~s}^{-1}$, the swell-induced 
momentum flux is shown to be linearly related to the square of the surface orbital velocity, which in turn is proportional to the swell significant wave height (the precise definition is in section 3) and the frequency of the dominant swell.

The aim of the present study is to use data from an oceanic experiment, Flux, État de la Mer, et Télédétection en Condition de Fetch Variable (FETCH), in the Mediterranean (Hauser et al. 2003; Drennan et al. 2003), to study the momentum transfer during low wind speeds and swell-dominated conditions. In section 2 the dataset is presented. In section 3 a basic analysis of the data is performed. Section 4 aims at a physical interpretation of the results, and section 5 includes a discussion and conclusions.

\section{Dataset}

The FETCH experiment (Hauser et al. 2003; Drennan et al. 2003) was carried out with extensive on-site measurements at a site in the Gulf of Lion in the northwestern Mediterranean Sea between 13 March and 15 April 1998. An Air-Sea Interaction Spar (ASIS) buoy (Graber et al. 2000) was moored $50 \mathrm{~km}$ offshore at a depth of $100 \mathrm{~m}$, roughly halfway between the French cities of Perpignan and Marseille. A three-axis sonic anemometer was mounted on top of the meteorological mast at $7 \mathrm{~m}$ MSL. An underwater motion package was installed to give the six components of motion of the buoy. Several experimental platforms were deployed during FETCH, but here data from only the ASIS buoy will be used.

The main purpose of the experiment was to study strong mistral and tramontane winds, which indeed did occur during the experiment. At the measurement site, these periods are characterized by growing seas and relatively short overwater fetches of about $50 \mathrm{~km}$. But there were also periods with lighter winds, long fetches, and swell waves that were not well described in the earlier publications. For the present study, a period with southeasterly winds and about $500 \mathrm{~km}$ of undisturbed fetch will be used.

\section{Data analysis}

\section{a. General atmospheric conditions}

During the FETCH experiment there were several swell events but only one that is characterized by distinct upward momentum flux during an extended period of time. This case lasts for about $22 \mathrm{~h}$, from 0846 UTC 22 March to 0646 UTC 23 March 1998, and included very pronounced upward-directed momentum flux for about $15 \mathrm{~h}$ (Drennan and Sahlée 2018). This is

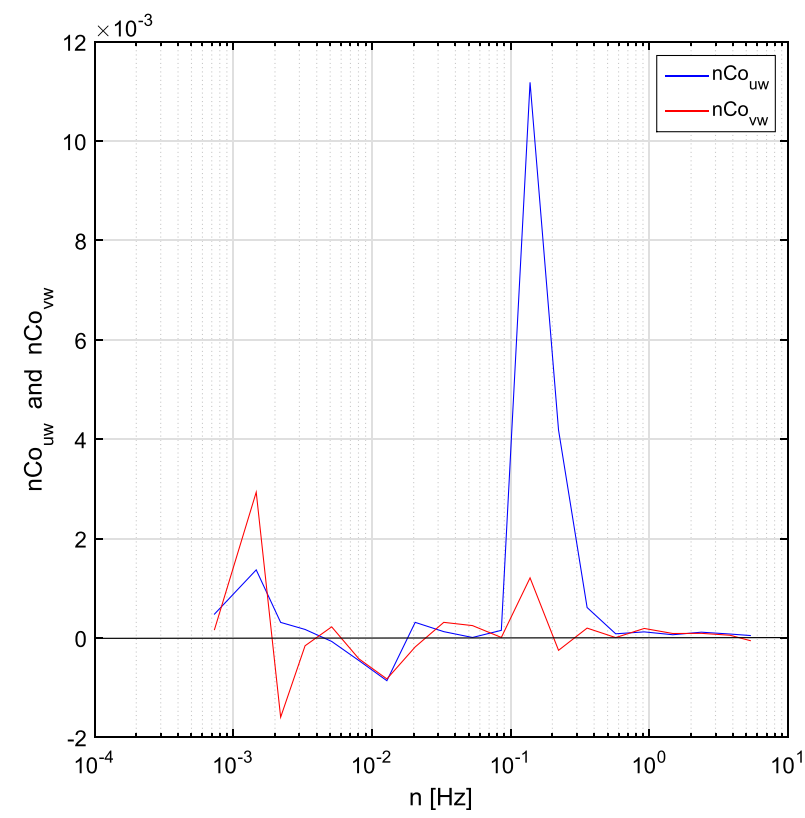

FIG. 1. Example of $u w$ cospectrum (blue) and corresponding $v w$ cospectrum (red) as a function of frequency for a case during low wind speed, $U_{7}=0.7 \mathrm{~m} \mathrm{~s}^{-1}$.

exemplified in Fig. 1, a low wind speed run that shows a strong peak in the wind velocity cospectrum at the swell frequency $n_{p}$ - see below for details. Below, we refer to the data during the 22-h-long swell period by run number $N, 1 \leq N \leq 44$, where $\Delta N=1$ corresponds to a 28.5-min sampling interval. For roughly 3 min each hour, the logging system was occupied with data processing and storage; thus, no measurements could be performed during this period. Note that this 22 -h swell case includes some low wind data that were excluded from the earlier Drennan et al. (2003) analysis, where the emphasis was on the wind sea.

The mean wave direction for the entire period, as measured by the ASIS buoy, was $105^{\circ}$ and the wind direction during the same period was $147^{\circ}$, which may, of course, not be representative of the long upwind fetch. In any case, we have a "wind-following swell case" in the sense defined in Högström et al. (2011). The upwind fetch is undisturbed for about $500 \mathrm{~km}$ for waves coming from the southeasterly direction.

Figure 2 presents time series plots for various parameters during the swell period. Figure $2 \mathrm{a}$ shows the wave age, $c_{p} / U_{7}$, where $c_{p}$ is the phase speed of the dominant swell and $U_{7}$ denotes the wind speed at $7 \mathrm{~m}$. Figure $2 \mathrm{~b}$ shows $U_{7}$. Figure $2 \mathrm{c}$ shows the bulk Richardson number, $\mathrm{Ri}_{b}=\left(g / T_{0}\right)(\Delta T)\left(z / \Delta U^{2}\right)$, where $g$ is the acceleration of gravity, $T_{0}$ is mean air temperature $(\mathrm{K}), \Delta T$ is the temperature difference between the air at $7 \mathrm{~m}$ and at the water surface, and $\Delta U$ is the difference $U_{7}-U_{0}$, where 

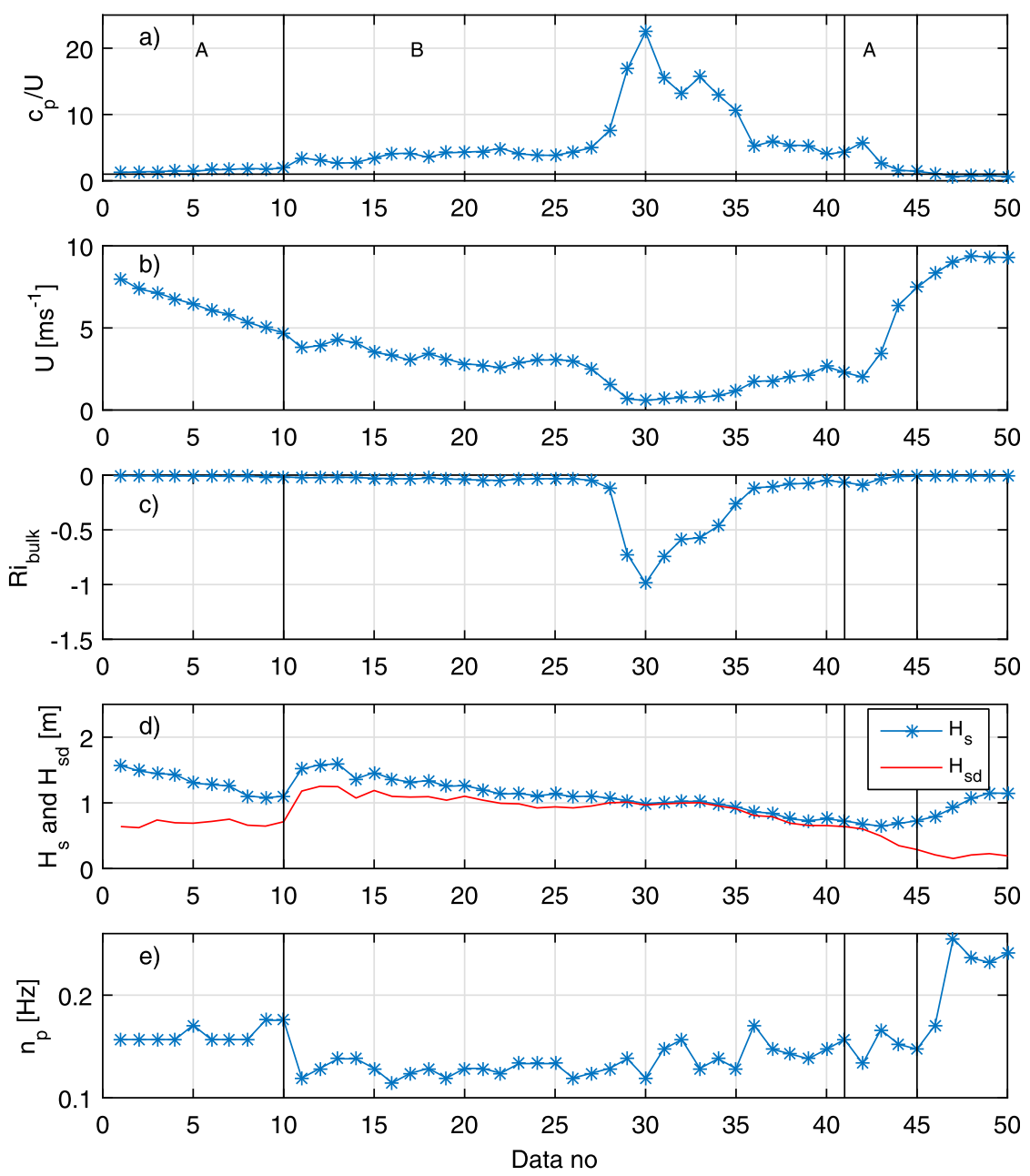

FIG. 2. Time series during the swell period: (a) wave age $c_{p} / U_{7}$, (b) wind speed at $7 \mathrm{~m}$, (c) bulk Richardson number, (d) significant wave height $H_{s}$ (blue) and significant swell wave height $H_{\text {sd }}$ (red), and (e) swell peak frequency $n_{p}$. Vertical lines indicate the limits for the ranges $\mathrm{A}$ and $\mathrm{B}$, respectively, where $\mathrm{A}$ includes cases with downward momentum flux and $\mathrm{B}$ includes cases with upward-directed flux. The solid horizontal line in (a) indicates $c_{p} / U_{7}=1$.

$U_{0}$ the surface wind speed, is assumed to be zero. The measurement height $z$ is $7 \mathrm{~m}$. Figure $2 \mathrm{~d}$ shows the significant wave height $H_{s}$ and the significant swell wave height $H_{\text {sd }}$. Figure 2e shows the swell peak frequency $n_{p}$. The regions denoted $\mathrm{A}$ in Fig. 2 contain data with downward momentum flux. Region B includes data with upward momentum flux. From Fig. 2a it is clear that almost the entire period, $1 \leq N \leq 44$, is dominated by swell. For reference, we include a further $3 \mathrm{~h}$ (to $N=50)$ where the swell remains, but it is dominated by a growing wind sea. The wave age parameter $c_{p} / U$ starts near 1 and increases to values above 20, decreases gradually to values around 5 at $N=36$, and further to 1.2 at $N=44$. The wind speed $U_{7}$ shown in Fig. $2 \mathrm{~b}$ decreases from approximately $7 \mathrm{~m} \mathrm{~s}^{-1}$ at $N=1$ to about $0.6 \mathrm{~m} \mathrm{~s}^{-1}$ at $N=29$ and then increases gradually to about $2.5 \mathrm{~m} \mathrm{~s}^{-1}$ at $N=36$. The bulk Richardson number shown in Fig. 2c is in the range $-0.1<\mathrm{Ri}_{b}<0$ for all data except for $27<N<38$, where it shows a very pronounced minimum down to -1 at $N=30$. Such large negative $\mathrm{Ri}_{b}$ values are indicative of a "free-convection regime." In this case it is caused not by a large heat flux but a very small $\Delta U$, with the wind speed at $7 \mathrm{~m}$ being less than $1 \mathrm{~m} \mathrm{~s}^{-1}$.

The wave parameters' $H_{s}$ and $n_{p}$ are shown in Figs. $2 \mathrm{~d}$ and $2 \mathrm{e}$, respectively. The value of. $H_{s}$ decreases from about $1.4 \mathrm{~m}$ at $N=1$ to about $0.7 \mathrm{~m}$ at $N=44$. Note that $H_{s}=H_{\mathrm{sd}}$ (for a definition of $H_{\mathrm{sd}}$ see section 3b) during a large portion of the period, confirming a minimal wind sea. The swell peak frequency is about $0.16 \mathrm{~Hz}$ in the initial period, $1<N<10$, then approximately constant, $0.13 \mathrm{~Hz}$ in the period $10<N<29$, increasing slowly to $0.155 \mathrm{~Hz}$ at $N=41$. 
The general synoptic situation during the measurement period of 22 and 23 March 1998 was dominated by a high pressure ridge with its center over the British Isles extending toward the southeast, giving weak winds at the FETCH measuring site. However, an area with closed isobars formed just east of the isle of Corsica on 21 March (southeast of the buoy location), moving toward Sicily during the next day. It is likely that this low pressure center was the source of the swell observed at the FETCH site on 22 and 23 March. From Fig. 2e it is clear that the peak swell frequency during the time period was between 0.12 and $0.14 \mathrm{~Hz}$. The corresponding relation between the phase velocity $c_{p}$ and $n_{p}$ in deep water, $c_{p}=g / 2 \pi n_{p}$, gives a peak swell phase speed of approximately $12 \mathrm{~m} \mathrm{~s}^{-1}$. The corresponding group velocity - that is, the speed at which the swell energy is propagated-is half the phase speed, or roughly $6 \mathrm{~m} \mathrm{~s}^{-1}$. Now the distance between the source area and the measurement site can be compared with the corresponding calculated traveled distance during the period when the low pressure area was formed, about $24 \mathrm{~h}$. The distance from the measurement site to the position outside Corsica (where the low pressure was first observed) is about $400 \mathrm{~km}$, and the corresponding distance to Sicily (where the low pressure was observed a day later) is of order $500 \mathrm{~km}$. These figures agree well with the calculated traveled distance during $24 \mathrm{~h}$.

\section{b. Wave data}

Waves on ASIS were measured with techniques described in Pettersson et al. (2003). We have evaluated one-dimensional wave spectra for each half-hour period included in this study. Figure 3 is a typical example (case $N=20$, where $U_{7}=2.73 \mathrm{~m} \mathrm{~s}^{-1}$ ). Here the spectral energy, $S(n)$, is plotted on a $\log -\log$ plot against frequency $n$. The general shape of measured wave spectra are quite similar throughout the swell period. These spectra exhibit a prominent maximum at frequency $n_{p}$, which for deep water corresponds to a wavelength $\lambda_{p}=g /\left(2 \pi n_{p}^{2}\right)$. In the particular example of Fig. $3 n_{p}=0.129 \mathrm{~Hz}$, which corresponds to $\lambda_{p}=96 \mathrm{~m}$. Also indicated in the figure is a straight line to approximate the high-frequency falloff (equilibrium range) in this representation. Following Smedman et al. (2003) we divide each spectrum into two parts, $E_{\text {swell }}$ and $E_{\text {windsea }}$, where $E_{\text {swell }}+E_{\text {windsea }}$ equals the total wave energy and $E_{\text {swell }}=\int_{0}^{n_{0}} S(n) d n$ contains the low-frequency energy, that is, the long waves. The swell significant wave height is defined as $H_{\text {sd }}=4 \sqrt{E_{\text {swell }}}$. We define $E_{\text {windsea }}$ as the energy of the waves at frequencies above $n_{0}$. The partitioning frequency $n_{0}$ is defined by the requirement that the corresponding wave phase speed $c_{0}=U_{10}$, where $U_{10}$ is the wind speed at $10 \mathrm{~m}$ (Smedman et al. 2003). The pressure-wave covariance

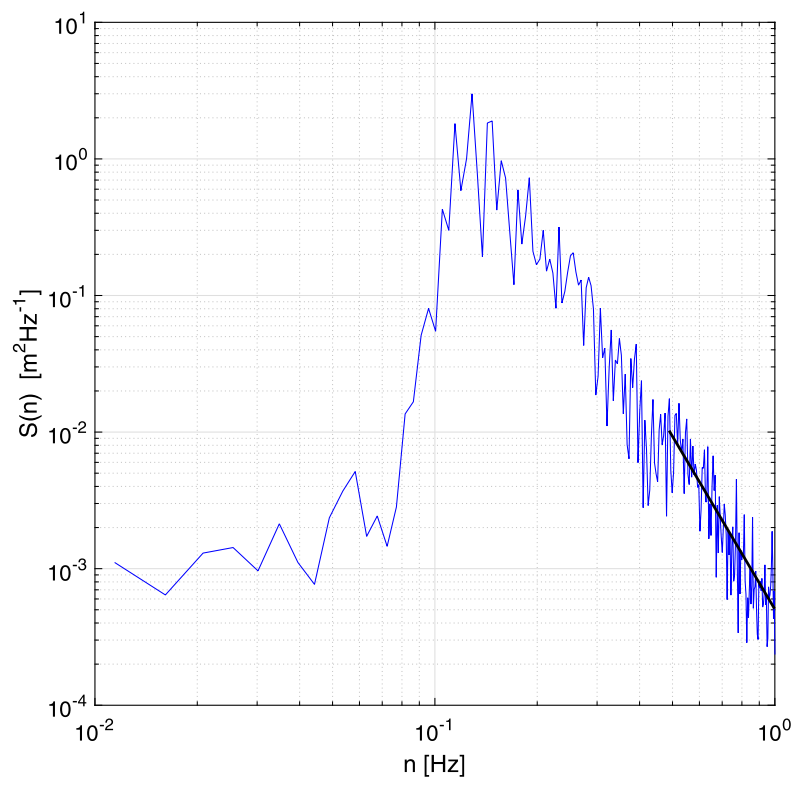

FIG. 3. Example of a one-dimensional wave spectrum $S(n)$ as a function of frequency $n$ in a $\log -\log$ representation. The spectrum represents half-hour measurements starting at 1830 LST 22 Mar 1998. The thick black line indicates a slope of $n^{-4}$.

measurements of Kahma et al. (2016) show that the spectrum of momentum flux between wind and waves changes its sign when $c_{0}\left(n_{0}\right)=U_{12}$. The fact that in swell-dominated conditions the wind velocity profile is nearly height constant above $7 \mathrm{~m}$ (Högström et al. 2013. 2015), so $U_{7} \approx U_{10} \approx U_{12}$, justifies our use of the 7-m wind measured at FETCH in the abovementioned relations. Hence, for deep water the phase speed $c=$ $g /(2 \pi n)$, so

$$
n_{0}=g /\left(2 \pi U_{7}\right) .
$$

Thus, for the example shown in Fig. $3, U_{7}=2.73 \mathrm{~m} \mathrm{~s}^{-1}$ and $n_{0}=0.58 \mathrm{~Hz}$.

Several studies have shown that when waves grow in a moderate or high steady wind and without interference of other wave systems-for example, swell-there is a range of frequencies sufficiently above the peak frequency where the spectrum can be described as (e.g., Kahma 1981)

$$
S(n)=\alpha_{u} g U_{10}(2 \pi)^{-3} n^{-4},
$$

where $\alpha_{u}$ is a dimensionless constant. When we integrate Eq. (2) using $n_{0}$ from Eq. (1), we find that

$$
E_{\text {windsea }}=\int_{n_{0}}^{\infty} S(n) d n=\frac{\alpha_{u}}{3} \frac{U_{10}^{4}}{g^{2}} .
$$




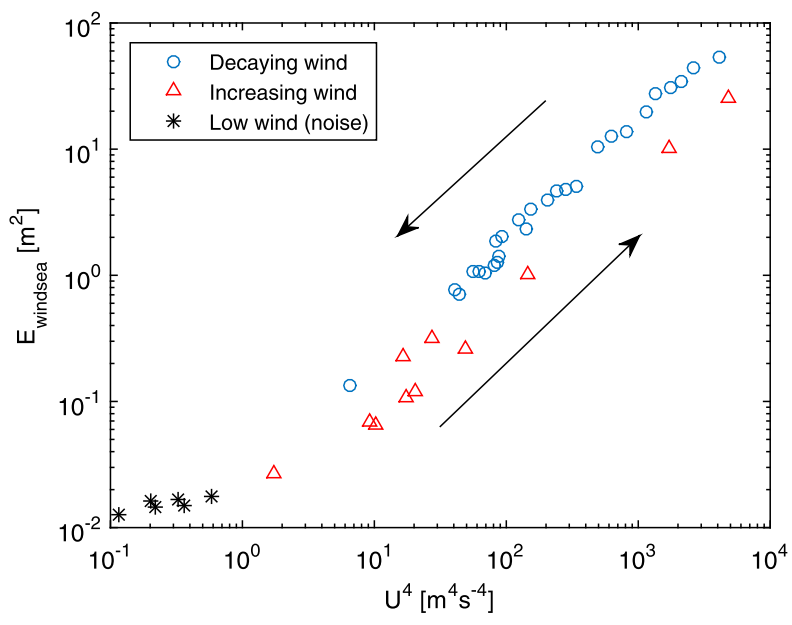

FIG. 4. $E_{\text {windsea }}$ as function of $U_{7}^{4}$. The arrows indicate the time evolution of the measurements starting with decaying wind, going down to low wind, and ending with increasing wind.

Experimental findings of $\alpha_{u}$ in ideal steady conditions range from 0.0045 (Kahma 1981) to 0.006 (Resio et al. 2004). A low value of $\alpha_{u}=0.0032$ was reported by Kawai et al. (1977), and similar low values are found in composite datasets [see Figs. 4 and 7 in Kahma and Calkoen (1992)]. The data here can evidently be divided into three groups, shown in Fig. 4. For the initial period when the wind decays to $2 \mathrm{~m} \mathrm{~s}^{-1}, \alpha_{u}=5.21 \pm 0.29 \times 10^{-3}$ (two standard errors, 27 runs). For the next five runs, where $U<1 \mathrm{~m} \mathrm{~s}^{-1}$, wind-sea energy [Eq. (3)] was below the noise level of the sensors; hence, the calculated $E_{\text {windsea }}$ does not represent wind-sea energy, but noise. This is evident in Fig. 4, with the low wind values (denoted by the asterisk) appearing well above the expected $E_{\text {windsea }}-U^{4}$ curve. For the remaining 11 runs, where the wind was typically increasing, $\alpha_{u}=2.37 \pm 0.66 \times 10^{-3}$ (two standard errors, 11 runs).

Laboratory experiments show that adding long mechanical waves dramatically reduces the growth of shorter wind-generated waves (e.g., Mitsuyasu 1966; Donelan 1987). Our data do not support this, since our data in the presence of strong swell are consistent with the previous wind-sea values, but rather agree qualitatively with Kahma and Calkoen (1992), showing no impact of moderate swell on the wind-sea equilibrium frequency range.

In Fig. $4, E_{\text {windsea }}$ is plotted as a function of $U_{7}^{4}$. The data points are plotted in a time-consecutive order, starting with $N=1$ on the uppermost right end of the group of circles and connecting with the stars, and ending with the triangles. Arrows in Fig. 4 indicate the temporal evolution. It is clear from Fig. 4 that $E_{\text {windsea }}$ is generally larger for a given wind speed when the wind is decreasing than at the same wind speed when the wind

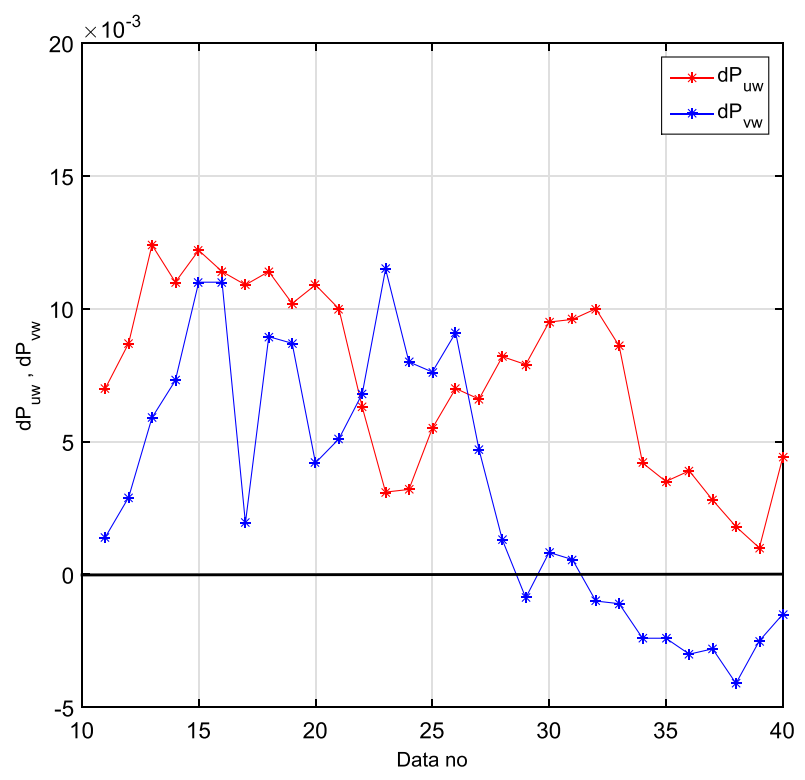

FIG. 5. Swell peak contributions $d P_{u w}$ (red) and $d P_{v w}$ (blue) to the shearing stress as a function of data number $N$ during the period $10<N \leq 40$

is increasing. A hysteresis effect is reasonable from a physical point of view, because $E_{\text {windsea }}$ is larger in the beginning when high wind has prevailed for some time compared to later when waves start to build up from a very low level. Equation (3) for $E_{\text {windsea }}$, determined only from the mean wind speed (i.e., with a prescribed constant value of $\alpha_{u}$ ), does not take such an effect into account.

\section{c. Stress contribution from cospectral peaks}

The contribution to the stress from the very apparent positive peaks in the cospectra, for example, Fig. 1, were evaluated with the same graphical method as was developed in Högström et al. (2015). The triangular approximation [Eq. (5) in Högström et al. 2015] gives for the $u w$ cospectrum

$$
d P_{u w}=\frac{n_{2}-n_{1}}{n_{p}}\left[n_{p} \mathrm{Co}_{u w}\left(n_{p}\right)\right]_{\mathrm{ampl}} / 2,
$$

where $n_{p}$ is the peak frequency and $n_{p} \mathrm{Co}_{u w}\left(n_{p}\right)$ is the corresponding amplitude of the cospectral peak, and $n_{1}$ and $n_{2}$ are the frequencies at the base of the triangular approximation.

In exactly the same way peaks in the $v w$ cospectrum have been evaluated,

$$
d P_{v w}=\frac{n_{2}-n_{1}}{n_{p}}\left[n_{p} \mathrm{Co}_{v w}\left(n_{p}\right)\right]_{\mathrm{ampl}} / 2 .
$$

Thus, a total peak contribution is obtained from 


$$
d P_{\text {tot }}=\sqrt{d P_{u w}^{2}+d P_{v w}^{2}} .
$$

Figure 5 gives $d P_{u w}$ and $d P_{v w}$ for the period $10<N \leq 40$, which is the period with an upward momentum flux, showing that $d P_{u w}$ (the red curve) is positive throughout the period; $d P_{v w}$ (the blue curve) is also positive initially, becoming slightly negative from around $N=30$.

\section{Physical interpretation of the results}

The complete spectral relation between the $u^{\prime}$ and $w^{\prime}$ fields is the complex spectrum $F_{u w}(n)$ obtained from Fourier analysis, where only the real part of $F_{u w}(n)$, that is, the cospectrum, contributes to the shearing stress:

$$
\overline{u^{\prime} w^{\prime}}=\int_{0}^{\infty} \mathrm{Co}_{u w}(n) d n
$$

The basic experimental results for the selected case from the FETCH experiment were given in Fig. 2 and discussed in section 3 .

Inspection of individual $u^{\prime} w^{\prime}$ cospectra, $n \mathrm{Co}_{u w}(n)$, reveals that all the cases from period A (as defined in Fig. 2) have downward-directed momentum flux. Calculations support the validity of the parameterization developed in Högström et al. (2015) (not shown). From $N>10$ and on to $N=40$ the momentum flux is upward. This flux is to a large extent provided by the dominant swell peaks at swell frequency $n_{p}$ (Fig. 1). In the case displayed in Fig. 1, the swell peak clearly provides virtually all the flux. This example is representative for FETCH cases with $U<$ $1 \mathrm{~m} \mathrm{~s}^{-1}$. Figure 6 shows a $u w$ cospectrum for a case with $U=1.8 \mathrm{~ms}^{-1}$ where, except for the swell peak, there is very little energy for $n>10^{-2} \mathrm{~Hz}$ but a considerable negative peak at $n=3 \times 10^{-3} \mathrm{~Hz}$. Such low-frequency fluctuations are common in this dataset for wind speeds below about $2.5 \mathrm{~m} \mathrm{~s}^{-1}$, but since they often change sign and frequency between successive runs, they seem to be random. Thus, in this case, it is reasonable to filter out this low-frequency noise by using a modified version of Eq. (7) to determine the shearing stress, that is, integrating from a certain low-frequency limit $n_{\text {low }}$ instead of from $n=0$. In the case of Fig. 6, the low-frequency limit $n_{\text {low }}$ is $10^{-2} \mathrm{~Hz}$. This limit is found to be reasonable for all observed FETCH cases with $U<2.5 \mathrm{~ms}^{-1}$. After application of the filter it is found that for these cases approximately $u_{*}^{2}=d P_{\text {tot }}$, where $u_{*}^{2}$ is the magnitude of the total surface stress, which is upward.

The cospectra in Fig. 7 are based on averages for all observed cases within four wind speed categories: $U<1.0 \mathrm{~m} \mathrm{~s}^{-1}$ (blue), $1.0<U<2.5 \mathrm{~m} \mathrm{~s}^{-1}$ (green), $2.5<U<3.4 \mathrm{~m} \mathrm{~s}^{-1}$ (red), and $U>3.4 \mathrm{~m} \mathrm{~s}^{-1}$ (black). It is seen that both the blue and green curves are close to

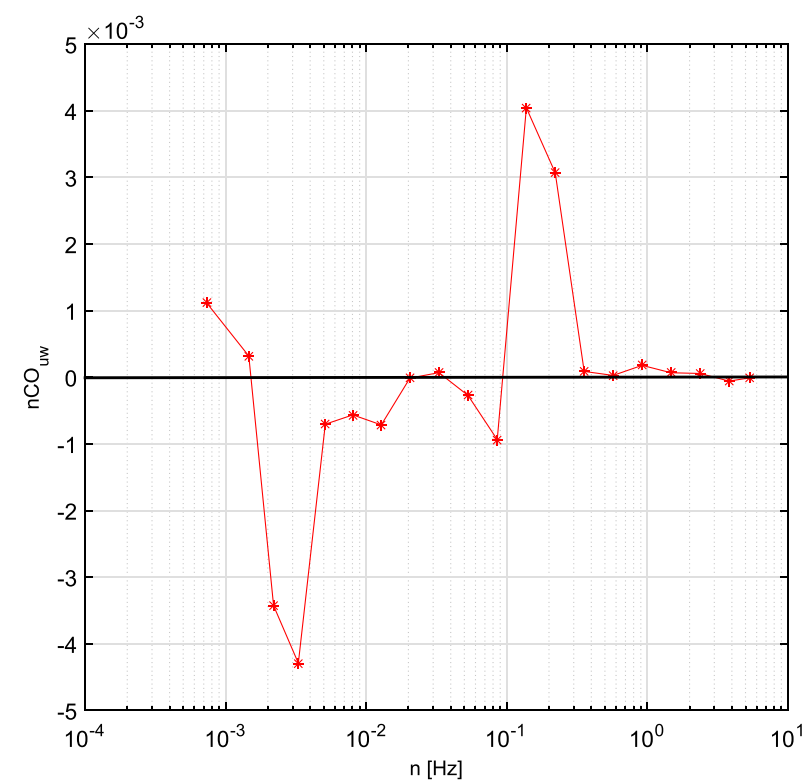

FIG. 6. Example of $u w$ cospectrum with $U_{7}=1.8 \mathrm{~m} \mathrm{~s}^{-1}$ (cf. Fig 1 ). Note very little cospectral energy (except the swell peak) for $n>10^{-2} \mathrm{~Hz}$.

zero in the frequency range $10^{-2}<n<10^{-1}$, in accordance with the abovementioned findings. In contrast, both the red and black curves have appreciable negative parts in the same frequency range, so for these cases $u_{*}^{2}$ is less than the contribution from the swell peak alone.

The swell peak contribution to the stress at the surface $d P_{\text {tot }}$ has been plotted against several possible parameters, with different symbols for the various velocity ranges (not shown). It is found that the only parameter that gives a coherent plot with low scatter is the swell wave height $H_{\text {sd. }}$. As shown in Fig. 8, all data with wind speed less than $3.4 \mathrm{~m} \mathrm{~s}^{-1}$ line up nicely along a linear fit, whereas the data with $U_{7}>3.4 \mathrm{~m} \mathrm{~s}^{-1}$ (black stars) stray away completely.

It is worth commenting on the very low wind speeds encountered during this study, as these points were removed from the earlier FETCH studies (e.g., Drennan et al. 2003). In particular note the black-filled triangles in Fig. 8, which denote the wind speed range $0.5<U_{7}<0.9 \mathrm{~m} \mathrm{~s}^{-1}$. Despite the very low wind speeds, these data fall on the same line as the remaining data and display only slightly larger scatter. This surprisingly good performance is due to the use of an asymmetrical sonic anemometer (Gill Solent 1012R2A) with a wide open sector without spars (in contrast to symmetrical sonics) mounted on the ASIS buoy mast. The buoy itself was kept oriented steadily into the wind by the long swell waves, so the wind flow was constantly through the wide open sector of the sonic. 


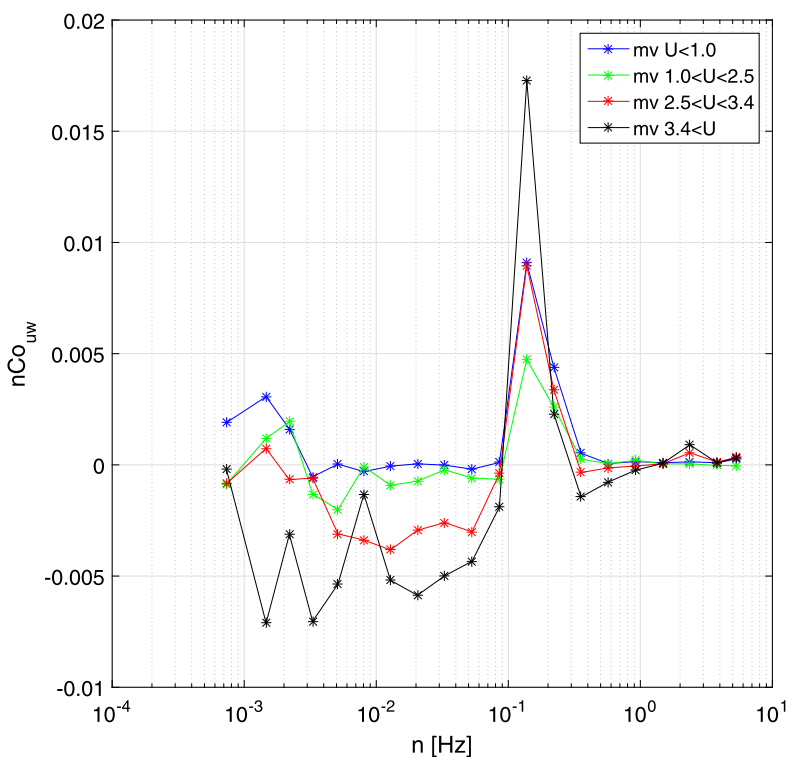

FIG. 7. Mean $u w$ cospectra for $U_{7}<1 \mathrm{~m} \mathrm{~s}^{-1}$ (blue), $1.0<U_{7}<$ $2.5 \mathrm{~m} \mathrm{~s}^{-1}$ (green), $2.5<U_{7}<3.4 \mathrm{~m} \mathrm{~s}^{-1}$ (red), and $U_{7}>3.4 \mathrm{~m} \mathrm{~s}^{-1}$ (black).

Figure 8 indicates clearly that there are two distinct regimes: 1) for $U_{7}<$ about $3.4 \mathrm{~m} \mathrm{~s}^{-1}$ all data gather along the line; and 2) for $3.4<U_{7}<4.3 \mathrm{~m} \mathrm{~s}^{-1}$ the data points (black stars) show a completely different behavior. To be able to interpret this result, we refer to the formal treatment of the stress budget at the surface by Högström et al. (2015), their Eq. (8):

$u_{*}^{2}=\underbrace{\left(D_{\tau}\right)_{\text {swell }}}_{\text {I }}+\underbrace{\left(D_{\tau}\right)_{\text {windsea }}}_{\text {II }}+\underbrace{\left(D_{\text {form }}\right)_{\text {windsea }}}_{\text {III }}+\underbrace{\left(D_{\text {form }}\right)_{\text {swell }}}_{\text {IV }}$.

Terms I and II represent tangential drag, where term I is the swell peak contribution and term II is the remaining tangential drag. Terms III and IV are waveform drag terms that give a downward contribution to the momentum flux for the wind-sea waves that move slower than the wind (term III) and an upward contribution for swell waves that move faster than the wind (term IV) (Högström et al. 2009). Thus, terms I-III give positive contributions to the total stress and term IV a negative contribution. In our present notation $d P_{\text {tot }}=\left(D_{\text {form }}\right)_{\text {swell }}$ and the two wind-sea terms can be considered zero during conditions presented here with strong swell and low wind speeds. What remains is the tangential stress caused by the swell, that is, the first term on the righthand side of Eq. (8). The surface can be dynamically rough if it is covered with ripples or dynamically smooth if ripples are absent, in which case the surface stress is

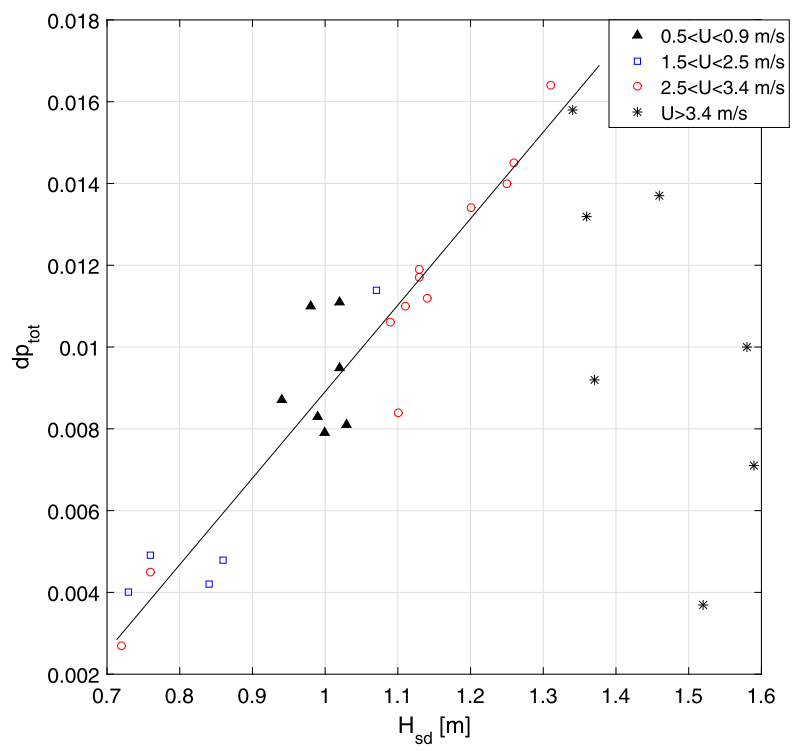

FIG. 8. Stress contribution from the cospectral peaks $d P_{\text {tot }}$ as function of significant swell wave height $H_{\text {sd }}$ for the upward flux data (cf. Fig. 2b). Colors and symbols mark different wind speed ranges $U_{7}$ (see legend).

entirely governed by molecular viscosity. This concept suggests a reasonable physical interpretation of Fig. 8 . For cases with $U_{7}>3.4 \mathrm{~m} \mathrm{~s}^{-1}$ ripples cover the water surface and the surface is dynamically rough, giving a broad cospectrum, as illustrated in Fig. 7. This figure, however, also shows that there is an appreciable range of low-frequency cospectral energy for the range $2.4<$ $U_{7}<3.4 \mathrm{~m} \mathrm{~s}^{-1}$. Nevertheless, for this wind speed range, the data for $d P_{\text {tot }}$ line up along the line (red symbols) in Fig. 8 together with the data for $U_{7}<2.4 \mathrm{~m} \mathrm{~s}^{-1}$. The tentative interpretation of this result is that ripples do occur for this wind speed range but are less widespread than in the case of $U_{7}>3.4 \mathrm{~ms}^{-1}$, but a better understanding of the mechanism involved is required. Additionally, note that the wind speed ranges presented here are based solely on the FETCH measurements and as such they cannot be considered universal. However, the wind speed limit for the onset of the upward momentum transfer during swell is similar to findings in other experiments (cf. section 5).

While the long swell waves dissipate very slowly, short waves grow and dissipate rapidly and adjust to the level supported by the energy input to waves at least in a steady state-but note the hysteresis effect displayed in Fig. 4. Kahma and Donelan (1988) measured the minimum wind speed for wave growth in neutral stratification to be about $0.7 \mathrm{~m} \mathrm{~s}^{-1}$. They also showed that a higher so-called critical wind speed must be reached in order for the short waves to reach a sufficient high steepness to be visible. Only in a perfectly steady wind 
and an infinitely long fetch and duration will these two be the same; otherwise, the critical wind speed will be higher and will depend on duration and fetch. Similä et al. (2006) and I. Heiler and K. Kahma (2018, unpublished manuscript) have empirically determined the fraction of the sea surface covered by visible short waves as a function of 2-min-averaged wind speed. A gentle swell was present at the same time. Figure 3 in Similä et al. (2006) shows that small patches of surface waves first appear at a wind speed of $1.2 \mathrm{~m} \mathrm{~s}^{-1}$ and will cover a few percent of the surface at $1.5 \mathrm{~m} \mathrm{~s}^{-1}$. The surface is fully covered by short waves at $3.3 \mathrm{~m} \mathrm{~s}^{-1}$ wind speed. These experimental results might offer an alternative interpretation of the FETCH results. Thus, the finding in Fig. 8 that $U=3.4 \mathrm{~m} \mathrm{~s}^{-1}$ forms a sharp separation between two regimes may be physically explained by ripples; that is, ripples are fully developed for wind speeds above this limit. In this context it is relevant to refer to the relatively new radar technology Wave and Surface Current Monitoring System (WaMoS II) from SeaImage Corporation, which enables measurements of waves from backscatter on centimeter-scale waves. It has been found useful for wind speeds above $3 \mathrm{~m} \mathrm{~s}^{-1}$ and wave heights above $0.5 \mathrm{~m}$ (Hessner et al. 2001, 2007). For lower wind speeds the backscatter signal becomes too weak as a result of the smoothness of the wave field.

Figures 1 and 7 display how remarkably narrow banded the exchange process is for the very low wind speed cases: outside the spectral peak around the dominant swell frequency $n_{p}$ there is virtually no cospectral energy. As discussed above, for cases with $U_{7}<2.5 \mathrm{~m} \mathrm{~s}^{-1}$ there is a pronounced "spectral gap" with virtually no energy in the frequency range $10^{-2}<n<10^{-1} \mathrm{~Hz}$. The isolated pronounced swell cospectral peaks give the impression of a process different from that of an ordinary turbulent boundary layer. A possible mechanism is found by Wen and Mobbs (2014) in their numerical simulations of laminar air-water flow of nonlinear progressive waves at low wind speed. In the simulation, water waves with zero current were continuously generated at the left end of the domain and propagated down the tank. Simulation results are presented for four wind speed alternatives: $U=0$, $U=u_{m}, U=0.5 c$, and $U=c$, where $u_{m}$ is the orbital velocity and $c$ is the phase velocity. The FETCH cases that gather along the line in Fig. 8 have typical $c$ values around $10 \mathrm{~m} \mathrm{~s}^{-1}, U$ about $1 \mathrm{~m} \mathrm{~s}^{-1}$, and $u_{m}$ around $0.3 \mathrm{~m} \mathrm{~s}^{-1}$, implying that the simulation cases for $U=u_{m}$ and $0.5 \mathrm{c}$ are closest to our smooth cases (i.e., those that gather along the black line in Fig. 8). The most prominent feature of these modeled cases is the presence of recirculation flow patterns in the air above the troughs, which are powerful mechanisms for upward momentum transfer. Wen and Mobbs (2014) stress the importance of the large wave slope encountered in their experiment, $2 a / L=0.08$, where $a$ is the wave amplitude and $L$ is the wavelength. Given that the typical wave slope for the FETCH cases is only $5 \times$ $10^{-3}$, it must be admitted that it is just speculation that this modeled mechanism might be valid for the FETCH cases. Wen and Mobbs (2014), however, showed simulation results only for one wave slope, making it difficult to know the sensitivity for waveform drag to wave slope.

\section{Discussion and conclusions}

From the FETCH experiment during low wind speeds the general conclusions are that the characteristics of the air-sea interaction regime during swell conditions are governed by wind speed $U_{7}$ and swell significant wave height. For measurements with $U_{7}>4.5 \mathrm{~m} \mathrm{~s}^{-1}$ the momentum flux is downward. This regime is in fact identical to the regime described in Högström et al. (2015). At lower wind speeds, a hysteresis effect was noted for the wind-sea energy $E_{\text {windsea. }}$. Momentum fluxes in both decaying and increasing winds around $4 \mathrm{~m} \mathrm{~s}^{-1}$ were upward. A reduction in downward stress in decaying winds in the absence of swell was noted by Drennan et al. (1999b) and is likely related to the wave age effect (cf. Drennan et al. 2003). At the swell magnitudes observed here, with the swell stress being upward, this reduction in downward stress is sufficient to result in overall upward stress.

For FETCH cases with $U_{7}<4.5 \mathrm{~m} \mathrm{~s}^{-1}$ the swell dominates and the momentum flux is found to be consistently upward. In the wind speed range $2.4<U_{7}<4.5 \mathrm{~m} \mathrm{~s}^{-1}$ the surface of the sea is covered by ripples [as supported by, e.g., Similä et al. (2006)], which influence the momentum exchange process at the surface to a degree dependent on wind speed. For observed cases with $U_{7}<2.4 \mathrm{~m} \mathrm{~s}^{-1}$ there are very few ripples, so the surface becomes close to dynamically smooth. For this regime, almost all of the momentum flux at the surface is due to the swell peak, and there is a linear relation with remarkably little scatter between the total stress contribution from the swell peak at the dominant swell frequency $n_{p}$ and the significant swell wave height $H_{\mathrm{sd}}$. This relation is valid for $H_{\mathrm{sd}}>$ $0.6 \mathrm{~m}$. For $H_{\mathrm{sd}}<0.6 \mathrm{~m}$ the total stress contribution from the swell peak is zero.

It is speculated that the strong peaks may be a result of the recirculation mechanism found by Wen and Mobbs (2014) in their numerical simulation of laminar air-water flow of a nonlinear progressive wave at low wind speed. The finding shown in Fig. $2 c$ that the Richardson bulk number was very large and negative for the very low wind cases, indicating a free convection regime, may offer an alternative mechanism for the observed phenomenon. 
The wind velocity limit for the onset of the regime with upward momentum transfer in the present investigation is similar to the results from Drennan et al. (1999a), who in their Fig. 10 report upward momentum flux at $U=$ $4-5 \mathrm{~m} \mathrm{~s}^{-1}$ for a strong following swell. Smedman et al. (1994) find upward momentum flux from concurrent mast measurements at $20 \mathrm{~m}$ and airborne measurements at $30 \mathrm{~m}$ during a period of several hours with wind speed $U<3 \mathrm{~m} \mathrm{~s}^{-1}$. There were no on-site measurements of waves during this experiment, but a wave hindcast from the Norwegian Meteorological Institute (Reistad et al. 2009) for the upwind area shows swell, as expected. In this experiment the upward momentum flux changed to downward when the wind speed increased above $3 \mathrm{~m} \mathrm{~s}^{-1}$.

Grachev and Fairall (2001) use data from the San Clemente Ocean Probing Experiment (SCOPE), where measurements were made from the Research Platform $(\mathrm{R} / \mathrm{P})$ Floating Instrument Platform (FLIP) off the Californian coast. Here, upward momentum flux was observed for $U<2 \mathrm{~m} \mathrm{~s}^{-1}$.

No doubt, many factors are likely to influence the onset of upward momentum flux, such as swell wavelength, swell steepness, and geostrophic wind, which are the three parameters used in the LES sensitivity test by Jiang et al. (2016). The exact limit in terms of wind speed when the transition from a downward to an upward momentum regime occurs apparently differs between studies. Perhaps this could also be related to the degree that short waves are influenced by the preceding wind conditions. This was demonstrated for our case by analyzing the quantity $E_{\text {windsea }}$ in decaying and increasing wind. More studies regarding such aspects of wave and wind interactions in quasi-steady conditions may be needed to better understand the parameter limits governing transitions between downward and upward momentum flux regimes.

\section{REFERENCES}

Donelan, M. A., 1987: The effect of swell on the growth of wind waves. Johns Hopkins APL Tech. Dig., 8, 18-23.

Drennan, W. M., and E. Sahlée, 2018: FETCH data. Uppsala University. Subset used: 22-23 March 1998, accessed 12 March 2018, http://urn.kb.se/resolve?urn=urn:nbn:se:uu: diva-345778

_, K. K. Kahma, and M. A. Donelan, 1999a: On momentum flux and velocity spectra over waves. Bound.-Layer Meteor., 92, 489-515, https://doi.org/10.1023/A:1002054820455.

_ H. C. Graber, and M. A. Donelan, 1999b: Evidence for the effects of swell and unsteady winds on marine wind stress. J. Phys. Oceanogr., 29, 1853-1864, https://doi.org/10.1175/ 1520-0485(1999)029<1853:EFTEOS > 2.0.CO;2.

,$- \ldots$ D. Hauser, and C. Quentin, 2003: On the wave age dependence of wind stress over pure wind seas. J. Geophys. Res., 108, 8062, https://doi.org/10.1029/2000JC000715.

Graber, H. C., E. A. Terray, M. A. Donelan, W. M. Drennan, J. Van Leer, and D. B. Peters, 2000: ASIS-A new air-sea interaction spar buoy: Design and performance at sea. J. Atmos. Oceanic Technol., 17, 708-720, https://doi.org/ 10.1175/1520-0426(2000)017<0708:AANASI >2.0.CO;2.

Grachev, A. A., and C. W. Fairall, 2001: Upward momentum transfer in the marine boundary layer. J. Phys. Oceanogr., 31, 1698-1711, https://doi.org/10.1175/1520-0485(2001)031<1698: UMTITM $>2.0 . \mathrm{CO} ; 2$.

Hanley, K. E., and S. E. Belcher, 2008: Wave-driven wind jets in the marine atmospheric boundary layer. J. Atmos. Sci., 65, 26462660, https://doi.org/10.1175/2007JAS2562.1.

Hauser, D., and Coauthors, 2003: The FETCH experiment: An overview. J. Geophys. Res., 108, 8053, https://doi.org/10.1029/ 2001JC001202.

Hessner, K., K. Reichert, J. Dittmer, and J. C. Nieto Borge, 2001: Evaluation of WaMoS II wave data. Ocean Wave Measurement and Analysis: Proceedings of the Fourth International Symposium Waves 2001, B. L. Edge and J. M. Hemsley, Eds., Vol. I, ASCE, 221-230.

— - _ J. Dannenberg, K. Hathaway, and D. Resio, 2007: 2D surface elevation measurements by means of X-band radar: An application of WAMOS II at Duck. Ninth International Workshop on Hindcasting and Forecasting, JCOMM Tech. Rep. 34, WMO/TD-1368, 13 pp., https://www.wmo.int/pages/ prog/amp/mmop/documents/JCOMM-TR/J-TR-34-9th-wavesworkshop/Papers/Hessner.pdf.

Högström, U., A. Smedman, E. Sahlée, W. M. Drennan, K. K. Kahma, H. Pettersson, and F. Zhang, 2009: The atmospheric boundary layer during swell: A field study and interpretation of the turbulent kinetic energy budget for high wave ages. J. Atmos. Sci., 66, 2764-2779, https://doi.org/10.1175/2009JAS2973.1.

, _— A. Semedo, and A. Rutgersson, 2011: Comments on "A global climatology of wind-wave interaction" by Kirsty E. Hanley, Stephen E. Belcher and Peter P. Sullivan. J. Phys. Oceanogr., 41, 1811-1813, https://doi.org/10.1175/ JPO-D-10-05015.1.

-, A. Rutgersson, E. Sahlée, A. Smedman, T. Hristov, W. M. Drennan, and K. K. Kahma, 2013: Air-sea interaction features in the Baltic Sea and at a Pacific trade-wind site: An intercomparison study. Bound.-Layer Meteor., 147, 139-163, https://doi.org/10.1007/s10546-012-9776-8.

- A. Smedman, E. Sahlée, A. Rutgersson, E. Nilsson, K. K. Kahma, and W. M. Drennan, 2015: Surface stress over the ocean in swell-dominated conditions during moderate winds. J. Atmos. Sci., 72, 4777-4795, https://doi.org/10.1175/ JAS-D-15-0139.1.

Jiang, Q., P. Sullivan, S. Wang, J. Doyle, and V. Linwood, 2016: Impact of swell on air-sea momentum flux and marine boundary layer under low-wind conditions. J. Atmos. Sci., 73, 2683-2697, https://doi.org/10.1175/JAS-D-15-0200.1.

Kahma, K. K., 1981: A study of the growth of the wave spectrum with fetch. J. Phys. Oceanogr., 11, 1503-1515, https://doi.org/ 10.1175/1520-0485(1981)011<1503:ASOTGO>2.0.CO;2.

, and M. A. Donelan, 1988: A laboratory study of the minimum wind speed for wind wave generation. J. Fluid Mech., 192, 339364, https://doi.org/10.1017/S0022112088001892.

_- and C. J. Calkoen, 1992: Reconciling discrepancies in the observed growth of wind-generated waves. J. Phys. Oceanogr., 22, 1389-1405, https://doi.org/10.1175/1520-0485(1992) 022<1389:RDITOG $>2.0$. CO;2.

, M. A. Donelan, W. M. Drennan, and E. A. Terray, 2016: Evidence of energy and momentum flux from swell to wind. J. Phys. Oceanogr., 46, 2143-2156, https://doi.org/10.1175/ JPO-D-15-0213.1. 
Kawai, S., K. Okada, and Y. Toba, 1977: Field data support of the three-seconds power law and $g u_{*} \sigma^{-4}$ spectral form for growing wind waves. J. Oceanogr. Soc. Japan, 33, 137-150, https://doi.org/10.1007/BF02109685.

Mitsuyasu, H., 1966: Interactions between water waves and wind (1). Rep. Res. Inst. Appl. Mech. (Kyushu Univ.), 14, 67-88.

Pettersson, H., H. C. Graber, D. Hauser, C. Quentin, K. K. Kahma, W. M. Drennan, and M. A. Donelan, 2003: Directional wave measurements from three wave sensors during the FETCH experiment. J. Geophys. Res., 108, 8061, https://doi.org/ 10.1029/2001JC001164.

Reistad, M., O. Breivik, H. Haakenstad, O. J. Aarnes and B. R. Furevik, 2009: A high-resolution hindcast of wind and waves for the North Sea, the Norwegian Sea and the Barents Sea. Norwegian Institute Research Rep. 2009/14, XXX pp.

Resio, D. T., C. E. Long, and C. L. Vincent, 2004: Equilibriumrange constant in wind-generated wave spectra. J. Geophys. Res., 109, C01018, https://doi.org/10.1029/2003JC001788.

Similä, M., I. Heiler, J. Karvonen, and K. Kahma, 2006: On C-band SCAR based oil slick detection in the Baltic Sea. Proceedings of SEASAR 2006: Advances in SAR Oceanography from Envisat and ERS Missions, H. Lacoste and L. Ouwehand, Eds.,
ESA Special Publ. SP-613, 6 pp., http://earth.esa.int/workshops/ seasar2006/proceedings/papers/186_simil.pdf.

Smedman, A.-S., M. Tjernström, and U. Högström, 1994: The near-neutral marine atmospheric boundary layer with no surface shearing stress: A case study. J. Atmos. Sci., 51, 3399-3411, https://doi.org/10.1175/1520-0469(1994)051<3399: TNNMAB $>2.0 . \mathrm{CO} ; 2$.

— , X. Guo Larsén, U. Högström, K. K. Kahma and H. Pettersson, 2003: Effect of sea state on the momentum exchange over the sea during neutral conditions. J. Geophys. Res., 108, 3367, https://doi.org/1029/2002JC001526.

Sullivan, P. P., J. B. Edson, T. Hristov, and J. C. McWilliams, 2008: Large-eddy simulations and observations of atmospheric marine boundary layers above nonequilibrium surface waves. J. Atmos. Sci., 65, 1225-1245, https://doi.org/ 10.1175/2007JAS2427.1.

Volkov, Y. A., 1970: Turbulent flux of momentum and heat in the atmospheric surface layer over a disturbed sea surface. $I z v$. Atmos. Oceanic Phys., 6, 770-774.

Wen, X., and S. Mobbs, 2014: Numerical simulation of laminar airwater flow of a non-linear progressive wave at low wind speed. Bound.-Layer Meteor., 150, 381-398, https://doi.org/10.1007/ s10546-013-9876-0. 